\title{
The Second Scientific Revolution in Capital Letters The Informatic Turn
}

\author{
Tamito Yoshida
}

The J apan Academy. 7-32 Ueno Park. Taito-ku. Tokyo 110-0007. J apan.

Tamito Yoshida is Member of the Japan Academy, Professor Emeritus at the University of Tokyo and the Chuo University. He was Vice-President of the Science Council of Japan. The text published here forms the basis of the keynote speech he delivered at the First World Congress of the International Federation for Systems Research held November 14-17, 2005, in Kobe, Japan. This was Yoshida's first (!) presentation in English to an international scientific audience. It is an outstanding resumé of his lifework worth taking into consideration outside Japan.

It was no later than 1993 when during his participation in a Japanese project aimed at clarifying information concepts, Yoshida introduced what he calls the "informatic" turn - an idea the origins of which date back as early as the late 1960ies. According to the paper presented here, it comprises a "genomic turn" of biological science, a "linguistic turn of the human and social sciences" and an "IT turn of engineering". The "informatic" turn marks a second scientific revolution compared to the revolution in which modern science itself was formed. This revolution leads to a new paradigm of science: science is fundamentally made for design, and it is fundamentally based upon the categories of "information" and "programme" which are defined in a fresh way to link philosophy-of-science considerations with semiotics.

Regarding the references, this paper may represent an exception from normal standards of scientific writing. Only a few Japanese sources are given. But we decided to publish it anyway, since the scientificity of the paper is beyond any doubt.

This paper was printed in the International Journal of Knowledge and Systems Sciences, Vol. 2, No. 2, September 2005. We publish this paper here in electronic form with kind permission of J AIST Press. Slight changes as to style and wordings are due to the editor.

- Wolfgang Hofkirchner - 


\section{Three Fundamental Postulates of Modern Science and the Transformation of 20th Century Science}

The metaparadigm of modern science taken as a whole originating from Newtonian mechanics - in contrast to the paradigms of individual sciences - as seen today, is made up by the three following propositions.

Firstly, the "purpose" of the knowledge called science is limited to "cognition" concerning the past, present and future of all nature from the material level through the biological level to the human level. This first proposition is called [...] "cognitive monism." The "nature" referred to in this keynote report is not limited to material and biological nature, but also includes human nature.

Secondly, the only "fundamental constituents" of all nature from the material level through the biological level to the human level are "matter and energy." Due to the fact that matter and energy have been recognized as different forms of the same thing since Einstein, this second proposition is called [...] "materialistic monism." Hereinafter, the three expressions of "matter and energy," "matter-energy" and "matter" have the same meaning.

Thirdly, the "fundamental principle of order" of all nature from the material level through the biological level to the human level are only "laws" that are deterministic/ stochastic and linear/ nonlinear. This third proposition is called [...] "nomothetic monism" or "pan-nomotheticism." Pan-nomotheticism includes both the view that each level of nature has particular laws that are irreducible to any other laws and the view that the laws of each level might eventually be all reduced to the laws of physics.

The three above propositions constituting the proto-metaparadigm of modern science could be criticized for being oversimplifying. However, they provide an effective means for clearly advocating the core of the issue of "the need and potential of a metaparadigm shift." Among the fruits of 20th century science, the theory of relativity and the quantum theory in the first half of the century, and if necessary, complex systems or nonlinear science in the second half, do not contradict any of these three propositions. However, some results of 20th century science had the effect of creating doubts about these three propositions.

1) The "use of science in technology" and the "use of technology in science" brought about in the 20th century led to the fusion of science and technology in what is referred to as "kagaku-gijutsu" in Japanese, meaning the unified body of science and technology. This fusion forced a reconsideration of "cognitive monism" in modern science. However, "science for society" (the resolution of practical issues) and "science for science" (cognitive

monism) remain separate and parallel, unintegrated at present.

2) Genetic information, neural information and computer information destroy and expand "information as natural language," and the term "information" has permeated throughout all academic fields, posing questions about its relation to "materialistic monism" in modern science. However, there is no systematic relation between the concepts of information used in individual specialist fields - especially between the natural sciences and the human and social sciences - at this point, and there has been no focus on its theoretical relation with material categories, such as monism or dualism. The relation between "information formed from fluctuations" in physics, "genetic information" in biology and "mass media information" in sociology is shrouded in complete darkness.

3) The discovery of the genome revealed that order on the biological level is a type of "special and variable order" (biodiversity) different from "nomothetic order assumed to be universal and unchanging," 
which raised questions about the "nomothetic monism" of modern science. The diversity of the material level is assumed to be eventually rooted in a single factor, that is, the special and variable nature of boundary conditions because the laws of physical science are universal and unchanging. However, diversity of the biological level is rooted in two types of factors, that is, genetic information and the boundary conditions determining its manifestation, and especially in the special and variable nature of genetic information. However, with regard to the scientific historical position of molecular biology and genomic science (the questions regarding whether genome theory is more revolutionary than relativity/ quantum theory, and whether the 20th century genome revolution is inside or outside the framework of the 17th century Newtonian revolution), the orthodox (proto-metaparadigm) interpretation based on physical reductionism has taken precedence, and at present, the genome has been given no interpretation beyond "boundary conditions of physical laws acting within living organisms." Molecular biology is considered to be the view of "organisms equated with molecular machines," which enabled the use of the terminology of physical science to discuss the enigma of life.

4) In relation to the human and social sciences, the connections between "information" and the "meaning, mind and spirit"; between "genomic order" and "ethical, conventional, contractual and legal order"; and between the "genomic turn of biological science" and the "linguistic turn of the human and social sciences" need to be questioned, but the divergence and fragmentation of the natural sciences and the humanities is not strongly conducive to this type of academic motive. Relativity and quantum theories affected philosophical thinking, but no philosophical discourse thoroughly following up the significance of the "genome" in philosophical thought and the history of thought has emerged to date.

\section{Three Alternative Proposals made by the Neo-Metaparadigm of Science}

Based on this situation in modern science, my new theory of science originating in my "evolutionary semiotics," which preceded international "biosemiotics" and was first published in 1967 to describe signs from DNA signs through neural signs to linguistic signs, was put forward in an attempt to make the following corrections to the three major propositions of modern science shown above.

Proposal of "designing science": Firstly, I redefine science with the purpose of "recognition of nature" as "cognizing science" (or epistemological science), and introduce a new form of science called "designing science," which integrates and expands the engineering in the natural sciences and the normative science/ policy science in the humanities. This is the design of the "desirable form" and the "righteous form" of nature, including its three levels mentioned above. The objective of science is expanded from "cognizing nature" to incorporate "designing nature," opening up the path to granting the "tradition of practical learning," which is as old as the history of humankind, rights as a form of scientific knowledge. This is a metaparadigm shift in the objective of modern science from "cognizing" monism to an integrated theory of "cognizing and designing." In order to avoid misinterpretation, designing science should be described not as "cognizing science about designing" but as "scientific activity with designing itself as the objective."

The basis of the scientific objective of ascetic restrictions on "cognizing," or such behavioral norms for scientists, is found in the relationship between "design" and "diverse values." In particular, this was a meta-axiology in which "the universality of values" that should be an assumption for "design" cannot be proven or demonstrated.

Designing science introduces the assumption of the theoretical-empirical falsification of the "provisional evaluative proposition," in concert with the theoretical-empirical falsification of the "hypothetical cognitive 
proposition" assumed by cognizing science, while also completely accepting "value-freedom" in both the sense of "freedom to values" (freedom of commitment to cognitive and practical values) and the sense of "freedom from values" (freedom of not being bound by values committed to) as required by sociologist Max Weber. This is the approach of the infinite progress of empirical self-reference distinguished from the infinite regress of logical self-reference, an expansion and generalization of Karl Raimund Popper's "falsification principle." The expanded and generalized "infinite progress of empirical self-reference" represents characteristics unique to the biological and human levels, which are unconnected with the material level, and a basic example can be found in "permanent natural selection of genetic information." Like cognitive propositions, evaluative propositions are also subject to falsification.

The "construction of evaluative space," which is made up of the two procedures of firstly the selective make-up of the set of evaluation criteria (evaluative programs) and secondly the synthesis of an overall evaluation (an evaluative information), is dependent on historical, cultural, economic, political, lifestyle, personal and various other conditions including the trade-off issue and priority issue of the evaluative proposition. How to theorize and practice the "empirical falsification of evaluative propositions" characterized by contextual dependence and situational relativity is a significant issue for designing science. This is the first area in which the "universalism" of the proto-metaparadigm of modern science needs to be reconsidered.

"Science for society" has obtained the new category of "designing science" to be theoretically integrated with "science for science" (cognizing science). The archetypes of knowledge found in the integration of stimulus and response, cognition and practice, "knowing that" and "knowing how," and knowledge of object and knowledge for use (Dr. Hiroyuki Yoshikawa), or what I call the "CD transformation of information" (conversion from cognitive information to directive information), have made a resurgence in "scientific knowledge." This is an attempt to integrate "cognizing science of systems" and "designing science of systems" on an equal scientific footing.

Proposal of evolutionary "information" categories: Secondly, in addition to the "matter and energy" that are the fundamental constituents of all nature, the constituents "nonsemiotic information and semiotic information" are introduced. From the perspective of the "history of concepts" of humankind, "matter and energy" is the application of science to the "hyle" category in Aristotle's philosophy, while "nonsemiotic information and semiotic information" is the application of science to the "eidos" category in Aristotle's philosophy. The application of science to the categories of "hyle and eidos" is the completion of the establishment of "matter and information" categories in scientific philosophy and scientific theory.

First, "nonsemiotic information" is a constituent penetrating all of nature in the same way as matterenergy, and is defined as the temporal, spatial, qualitative and quantitative differences and patterns of matter-energy." Nonsemiotic information, or "differences/patterns" are basic categories included in the category of matter in the protometaparadigm in the form of "attributes, properties, features, characteristics, qualities,

quantities, dimensions, units, etc." that were not noticed or pointed out as being such. Where there is matter, there are always differences/patterns borne by it, and wherever there are differences/patterns, there is always matter bearing them. Both are one and the same. Using an Aristotelian expression, the category of matter in the proto-metaparadigm is "an indivisible entity of matter as substance (hyle) and differences/patterns (nonsemiotic information) as its essence (eidos)," or could be understood as the "synolon of hyle and eidos"(hylomorphic entity) in Aristotle's philosophy. In a word, "matter" as in protometaparadigm connotes "differences/patterns" as its unnoticed elements.

In that respect, the proto-metaparadigm has already unknowingly assumed "nonsemiotic information" categories using the diverse natural and technical languages described above. The neo-metaparadigm 
explicitly abstracts and generalizes these differences/patterns (even if the differences/patterns of matter may not be self-existing unrelated to the difference / pattern-ladenness resulting from individual/social information mechanisms of human sensomobility and language), raising their status to fundamental constituents penetrating all of nature. This elevation is an essential theoretical step for deriving the category of "semiotic information" as opposed to "nonsemiotic information," and therefore the human level categories of mind, meaning, spirit and "god" as higher forms of semiotic information, from the material level.

Of the "differences/patterns" adopted as the definition of nonsemiotic information, "differences" succeed linguist F. de Saussure's pan-informational insight transcending the framework of linguistics, and "patterns" expand and generalize pattern as in the "pattern recognition" of computer science. The "simultaneous occurrence of differences and patterns" is a tautologous concept in which "differences exist based on patterns and patterns exist based on differences," or "differentiation is the differentiation of patterns, and patterning is the patterning of differences." This is a method of definition chosen in order to avoid an "infinite regress of definition" regarding "elementary words." "Differences" or "patterns" are used depending on whether the context and situation in which "differentiation" should be stated or the context and situation in which "identification" should be stated.

Semiotic information is next. "Semiotic information" with DNA information as its evolutionary origin and progressed to linguistic information and digital information, is a constituent unique to the biological and human levels, and is defined as a physical coupling or representation-mediated coupling between "differences/patterns of matter functioning as signs" (endosigns and exosigns) and "differences/patterns of matter functioning as their meaning" (objective meaning or referent, and representative meaning or representation as meaning). Examples of differences/patterns in semiotic matter include the linear sequence pattern of AGCT elements in DNA information and the linear sequence pattern of printed letters of the alphabet that make up the information elements in law. If changes in DNA information are changes in linear sequence patterns of AGCT, revisions to the law are changes in linear patterns of printed letters. Of course, patterns/differences in semiotic material are not limited to one-dimensional linear sequences, as can be seen in the example of neural network patterns.

"Semiotic evolution" is divided into "evolution of the semiotic vehicle" and "evolution of the semiotic form." Matter in which differences/patterns function as signs that could be called "semiotic matter or semiotic vehicles" is found in various forms including polymers, neurons and substances outside living organisms, creating first various endosigns carried by matter inside living organisms, then exosigns carried by matter outside living organisms. This is the outline of semiotic vehicle evolution. Inner speech focuses on endosigns while outer speech focuses on exosigns. Meanwhile, the "semiotic form" evolved from signals created on the biological level to symbols created on the human level. These are the two basic phases of the evolution of semiotic form. "Signals" such as genetic signs (DNA signs), hormones, pheromones and sensorimotor signs are "a semiotic form in which signs and their referents are physically linked and always have referents, but do not have any representative meaning," while "symbols" such as icons and language are "a form of sign in which signs and their representative meanings are physically linked in the brain as a result of learning and always have representative meanings, but may not always have referents, and even if they do, they may only be linked to referents through representations as meaning."

"Representations" that are created at a certain stage of evolution of the cerebral nervous system were not primary themes in either the Anglo-American semiotics of C.S. Peirce or the continental semiology of Saussure. However, evolutionary semiotics, which employs the concepts of DNA signs and neural signs interprets "representation" as a type of sign. This is positioned as a transitional sign form between signal and symbol, and is called a "one-term symbol" in contrast to a normal symbol combining semiotic representation (signifiant) and meaning representation (signifié), or a full-fledged "two-term symbol." This 
is because it lacks the real-time "stimulus constraints" or "response constraints" seen in sensation/perception or motion/ movement neutral sign as signals.

The semiotic information space most characteristic of the human level is the human mental and linguistic "representative space" or the "one-term/two-term symbolic information space" that is markedly expanded and improved through the acquisition of "language." If "evolution on the biological level" is originated from "variations in the DNA information space," this is paralleled by "evolution on the human level" being originated from "variations in the representative information space." If nothing else, from the perspective of evolution, the significance of the "representative information space" on the human level is equal to the significance of the "DNA information space" on the biological level. Scientific revolution, technological innovation, revolutions in values, institutional reforms and new styles of art are all rooted in variations within the representative information space of humans. "A rich world of meaning" refers to none other than "mental and linguistic representative information space with rich differences/patterns," and the "degree of fluctuation" in mental and linguistic representative information space, namely one-term/twoterm symbolic information space is directly linked to the advancement of human society. "But the mattercentered proto-metaparadigm is not clearly aware of this.

"God" was defined by Aristotle as "pure eidos without hyle" but this was ignored or dispelled by orthodox science, without being able to position it. However, the neometaparadigm provides a definition for "god" as a certain type of human construction (artificiality) of "a pure representative space for which the existence of a referent is not, need not to be or should not be questioned." Artificialities of pure representative space such as "god" or an "absolute being" are identical to material, biological and social artificialities (human constructions) in that they are both positive and negative for humans. Of course, representative space (semiotic information space of representation) including pure representative space cannot exist without hyle or a material basis forming neural paths.

This is a metaparadigm shift regarding the fundamental constituents of nature from the

monism of "matter" to the dualism of "matter and information." Strictly speaking, the dualist approach of "matter and information" is "derivative dualism originating from Ur-monism." "Ur-monism" refers to the natural philosophy in which the "indivisible entity" of "matter as substance" and its "nonsemiotic information as differences/patterns" is the sole constituent of the material level, and the biological and human levels are unavoidably and essentially based on this indivisible entity of the material level. This is a monist theory of "matter and its differences/patterns in unity", namely hylomorphic entity. In contrast to this, "derivative dualism" signifies a dualism of "matter and semiotic information" peculiar to only the biological and human levels. This is the evolution from "nonsemiotic information" to "semiotic information" in which a monistic material nature (hylomorphic entity) becomes dualist with the birth of life. Specifically speaking, it means the division of "a hylomorphic entity functioning as a sign" and "a hylomorphic entity functioning as meaning," the division of "coding hylomorphic entity" and "coded hylomorphic entity," or the division of giving meaning and being given meaning in the biological and human levels of nature.

Both sign and meaning, that is, endosigns and exosigns, or object meaning (referent) and representation meaning (representational meaning) are, if considered as itself separated from each other, not different from "matter and its differences/patterns in unity." If this point is focused upon, a "panmonistic worldview" is possible. However, the physical/ representational "coupling" of "matter and its differences/patterns" in the two systems of "sign" and "meaning" led to the derivation/ creation of the dualist world characterized by the three major information functions of "direction, cognition and evaluation" in the biological level and human level. Directive, cognitive and evaluative signs are differences/patterns in matter-energy, but they also lade differences/patterns on their respective referents and representational meanings as matter-energy. In Gregory Bateson's terms, this is nothing else than "a difference/ pattern that makes a difference/ pattern." 
The most simplified essence of dualism particular to the biological and human levels derived from the monistic material level can generally be abstracted as follows. "Differences/patterns of matter" as "signs" designate, express and construct "differences/patterns of matter" as "referents" through the three major information functions, or three modes of information functions, comprised of cognition, evaluation and direction. On reflection, this is a cyclic relationship in which "differences/patterns of matter" as "referents" directly or indirectly determine "differences/patterns of matter" as "signs" through some form of selection process (the empirical self-reference mentioned above). Specific examples are the cyclical relationship in which cognitive, evaluative and directive symbolic information space of humans creates a human reality, and human reality determines symbolic information space through ex ante and ex post human selections and the cyclical relationship in which the genotypes of organisms construct their phenotypes and phenotypes determine genotypes through natural selection.

Cartesian "dualism" on the level of the higher nervous system and the dualism of "protein and nucleic acids" on a cellular level are two typical examples of "derivative dualism" that have emerged in the world of human knowledge. If theorization is performed without fear of being criticized for being too abstract, the "sign - meaning" coupling between "semiotic matter designating, expressing and constructing the differences/patterns of semantic matter" on the one hand and the "semantic matter in which differences/patterns are designated, expressed and constructed through semiotic matter" on the other, in a word, the coupling between "coding differences/patterns" and "coded differences/patterns" can also be observed in the immune system, the endocrine system and the lower nervous system. These could be called respective types of dualism. The duality of the real world and the internet world is also a type of dualism, even if not in the Cartesian sense of dualism.

The following nested structure has also to be indicated. In its relationship with genetic information (directive signs), protein is its referent, but enzyme protein is the directive sign in its relationship with the chemical reactions (referents) in which it acts as a catalyst. If the philosophy about nonsemiotic and semiotic information were called "information philosophy," this would imply that anthropocentric idealism and mentalism were extremely limited information philosophies. Incidentally, the proto-metaparadigm positions the existence of specific enzyme protein coded by the genome (with DNA information as a blueprint) as a boundary condition of an in vivo chemical reaction, which is to be discussed below in connection with physical reductionistic view of life.

The three major information functions of cognition, evaluation and direction do not exist in the material level not containing semiotic information, and are functions particular to semiotic information inherent to the biological and human levels. This means that the three major information functions are not limited to the human level. The three major information functions have also already been observed in primary macromolecular information processing. For example, the synthesis of protein is the result of the "directive function" of DNA information, and the chemical recognition (realized in key-keyhole relationships) of substrates achieved through enzyme protein is a "cognitive function," while the adjustment of "catalytic activity" and "synthesis of the enzyme itself" resulting from in vivo synthesis and resolution reactions catalyzed by the enzyme is the "evaluative function" DNA information could be supposed to have obtained as a result of natural selection.

Each of these is an evolutionary archetype of directive, cognitive and evaluative semiotic information functions. Sensory, emotional and motory types of cognition, evaluation and direction, in addition to linguistic types of cognition, evaluation and direction are their higher forms in cerebral nervous information processes. Immune reactions related to antigens and antibodies do not work without "cognition and direction." The structures on the surface and inside cells that specifically couple with special substances outside cells are called receptors, and they are involved in both cognition and direction. The initial metaphorical interpretation can lead to new scientific cognition. 
Proposal of the "program" category: Thirdly, and finally, "laws" held to be the only fundamental principles of order for all of nature are limited to the physical level, and a new basic category called the "program" is introduced as a principle of order unique to the biological level and the human level. "Programs" ranging from the "DNA programs" that are their evolutionary archetypes to sensorimotor programs and linguistic programs, together with computer programs as "forms of programs with scientific technology applied" are the principle of order made up of "signs" in some evolutionary stage intrinsic to the biological and human levels of nature. To use a metaphor, they are "spatiotemporal blueprints." As a principle of order made up of signs intrinsic to biological and human nature and characterized by speciality and variability as a result, this is a principle of order which is of a completely different type to the universal and unchanging "laws" (laws of physical science, physical laws and chemical laws) that are unrelated to the signs intrinsic to nature. This is the second area in which the "universalism" of the proto-metaparadigm needs to be rethought.

However, as introducing concepts originating from natural science into the humanities is routine in the proto-metaparadigm, a principle of order assuming the category of "sign" originating from the humanities, or the non/anti-physical science-type abduction of a principle of order borne by signs intrinsic to nature, is susceptible to appear "anthropomorphic and therefore unscientific" to natural scientists and especially physicists. However, the involvement or noninvolvement of signs intrinsic to nature or intrinsic to objects is the greatest characteristic separating programs and physical laws. All principles of order including Newtonian laws, genetic programs and positive laws are described and expressed using signs on the side of humans, but this does not refer to this meaning of the involvement of signs. Newtonian laws are described and expressed using the terminology of mechanics, but there are no signs within the movement itself that is the object of Newtonian laws, and this is the reason Newtonian laws are unconnected to any signs intrinsic to objects. However, genetic programs described and expressed using the terminology of genome science are made up of DNA signs intrinsic to the side of the objects of cognition, or the actual cells. It need not be said that positive law, which is a typical program in a law-governed country, is made up of linguistic signs. Both the genome and positive law are described using language, but the evolutionary stages of the signs intrinsic to their objects differ. This is the reason evolutionary semiotics is essential to programmatic science.

The neo-metaparadigm interprets the discovery of the "genome" as that of the missing link of "evolution of the principle of order" from "laws of physical science" on the material level to "conventional and legal rules" on the human level. As a result, "order as conventions and arrangements" such as the customary and legal order of the human level (I will refer to this generically as rule-based order below) has gained a place in the "overall image of nature" for the first time in the academic history of humankind as part of a "naturalistic view about order in three levels of nature." "Rule-based order on the human level" has been faced with questions regarding its significance in the human world, but although questions regarding its significance in the universe and the world have been posed by "religion," they have not been posed from the perspective of science. Even if they were, "science" had no answers. However, prior to "rules as spatiotemporal blueprints of social systems," there was already the "genome as a spatiotemporal blueprint of biological systems." This was nothing less than the discovery of the "missing link in the evolution of the principle of order." This is a radical metaparadigm shift from "nomothetic monism" regarding the principle of order in nature to "evolutionary theory of the principle of order". The "program, or spatiotemporal blueprint of the biological and human levels" made up of signs in some stage of evolution is one of the subordinate concepts of "semiotic information" as a "set of signs." Therefore, firstly, in contrast to the principle of order: laws that are assumed to be unchangeable, programs made up of signs are a changeable principle of order. The arrays of bases, phonemes, letters and the binary code making up programs can change. If a principle of order cannot be called such without being unchangeable, this is nothing but a corollary of the nomothetic monism principle of order. 
Secondly, "signal-type programs" made up of signals physically coupled with referents, such as DNA programs and sensorimotor programs, operate according to physical science and cannot be violated unless a fault (for example, endocrine disrupting chemicals also known as environment hormones) occurs. However, visual and linguistic programs such as architectural blueprints, conventions, laws and artistic styles are made up of symbols only coupled with referents through representations, and as a result it is natural that there is a possibility of ambiguous interpretations and violations (deviations). This is freedom unique to the human level and is inextricably linked to vulnerability. If a principle of order cannot be called such without being inviolable, this is also nothing but a corollary of pan-nomothetic monism.

There are no physical scientists that do not mention the laws of physical science when discussing order on the material level. However, at this point in time, it seems there are no biological scientists who refer to "genomes" that operate within living organisms and the "laws of physical science" that act also inside living organisms supporting and restricting these, and at the same refer to the "laws unique to organisms" separate to these, which might be the laws of physical science particular to living organisms or biological laws particular to living organisms. This implies there are "genomes" on the biological level but no "biological laws." If this is the case, there are laws on the material level but no laws on the biological level. However, the idea of laws existing on the human level is not very convincing based on the view that there are consistent trends in natural evolution, a special case of "uniformity of nature" assumed in science. However, orthodox social sciences to date have had the view that there is a "nomothetic order" in addition to a "rule-based order." In terms of the biological level, this means there are "biological laws" in addition to "genomes."

However, is this really the case? Could it be that the areas in psychology seen as being "laws" were the direct or indirect effects of the operation of genetic programs, cultural programs or other learned neural programs, and if not, empirical generalizations? So-called "economic laws" are nothing more than misconceptions of "economically rational programs" of an ideal being named homo economicus and the "repercussions of its synthesis," and in particular their "mathematical structure." All "rational programs" are the same as all "customary programs" in that they are symbol-type programs. "Game theory" and "rational choice theory" belonged to "programmatic science" and not "nomothetic science." There was a tendency to renounce or refute the study of law of being a "science" under the pan-nomotheticism of the protometaparadigm, and position it as a "technology." However, it is now seen to be a programmatic science that is representative of the social sciences. Law (legal programs) devoted to resolving problems on the human level is as "technology" exactly the same as physical engineering programs devoted to solving problems on the physical level and biological engineering programs devoted to solving problems on the biological level, but the content of these technologies is all some form of "symbol-type program." Of course, prior to the interpretation of "legal programs" being social technology, the interpretation of legal programs should be extended to suggest they are the basic principles of order for society in general equal to "ethical programs" and "customary programs" of modern law-governed society, replacing "illusory social scientific laws." "Legal science" cannot be realized as the "nomothetic science" of the protometaparadigm and is only realized as "programmatic science" of the neo-metaparadigm. Put differently, the appearance of the neo-metaparadigm of modern science has a special

significance for "science of law."

Even if the principles of order on the biological and human levels are programs, there may be some form of "laws" regarding these programs (regarding, for instance, their formation, maintenance, transformation and extinction). Even if an explanation can be given using "programs" instead of "laws," there may be "laws" explaining those programs.

This is an obvious question. The neo-metaparadigm is saddled with the issue of "the program as an explicandum (dependent or explained variable) as opposed to "the program as an explicans (independent 
or explaining variable)." Darwinian theory has already been adopted as the mainstream in biological science to explain genetic programs. It cannot be said that a final conclusion has been reached regarding evolution including Darwinian theory. However, my neo-metaparadigm adopts an extension of Darwinian theory, or Pan- Darwinism, regarding "the program as an explicandum." I will discuss the general framework in Section V.

As seen in the argument above, the "design" concept in this paper is used as a "scientific construct" referring to all phases of "formation, maintenance, transformation and extinction" of signal-type and symbol-type programs through the "variation and selection" mentioned below. "Mutation and natural selection of genetic programs" and "free conceiving and human selection of linguistic programs" are two typical examples of "design." The "spontaneous order" put forth by Hayek can also be interpreted as "unplanned and ex post selective design." The "construction" paired with "design" is also an extension of natural language. Abduction, which is distinguished from induction and deduction, requires what I call a forward-looking "method of concept creation" and not a backward-looking "method of dictionary making." In particular, the creation of a theoretical framework crossing the humanities and natural sciences cannot be achieved without breaking through the "restrictions of natural language and existing language." The new scientific language is actually forced to be based on existing language including natural language of the world we live in, but existing language including natural language has historically changed through the new scientific language of the scientific community. This cyclic relationship cannot be disregarded in the long term, but the cutting edge of academia must constantly break the fetters of the common knowledge of the time signified by natural language and existing scientific language.

In summary, laws on the material level are "unchangeable and inviolable principles of order," signaltype programs on the biological level are "changeable and inviolable principles of order," and symbol-type programs on the human level are "changeable and violable principles of order." The natural evolution of the principles of order increased the degree of freedom first from "unchangeableness" to "changeableness" and then from "inviolability" to "violability." The human pursuit of freedom is backed by this evolutionary trend of "increasing the freedom of the principles of order (however, this claim is a philosophical proposition and not a scientific proposition). The proto-metaparadigm positioning of "free will," "individuality" and "existential man" that posed problems under "pan-nomotheticism" are all refuted as pseudo-issues, and they are faced with the new aspects of the cognitive issue (descriptive issue) and the design issue (normative issue) of "human diversity of symbol-type program" and "human form of its variation and selection."

This is one example of the philosophical effect of the neo-metaparadigm. Here I will attempt to explain the degrees of freedom in the three levels of nature from the perspective of "contingency." This is an applied problem for the neo-metaparadigm. In general, "freedom of order" refers to "the potential for order to be in a different form to that of the present," that is, "the potential to be different," and is called "contingency" (a state, existence or order that is possible but not necessary, or in terms of modal logic, a negation of both "impossibility" and "necessity"). As the suppression of human freedom is the suppression of human contingency, contingency has traditionally been discussed in terms of the human world. However, the neo-metaparadigm argues that contingency in the three levels of nature has evolved as follows. Firstly, contingency in the nomothetic order of the material level is guaranteed by the changeableness of its "boundary conditions" (strictly speaking, "boundary conditions in the broad sense of the term" including both "temporal initial conditions" and "spatial boundary conditions, or boundary conditions in the narrow sense of the term.") The contingency of chaos (a type of complex system) that obeys deterministic laws but acutely reacts to the smallest of differences in initial conditions (an example of boundary conditions) could be seen as a notable example. Secondly, contingency in the signal-type programmatic order of the biological level is guaranteed by not only changeableness of its boundary conditions, but also changeableness of programs themselves. Biodiversity is mainly created through 
diversity in genetic programs. Thirdly, contingency in the symbol-type programmatic order of the human level is guaranteed by not only changeableness of its boundary conditions and programs, but also violability of programs themselves and the design format of programs ("free thought and endogenous or internal selection" of programs and not "mutation and exogenous or external selection" of programs). In particular, linguistic programs could be free selections that never recur.

In summary, contingency in the material level, biological level and human level differs both qualitatively and quantitatively. However, in "nomothetic monism," "contingency in all of nature" is theoretically all uniformly guaranteed by only the changeableness of "boundary conditions of laws," and the qualitative and quantitative differences in contingencies in the material level, biological level and human level cannot be distinguished at all. However, "existential being" - that is a type of being unique to humans - is only made possible by assuming unique contingency in the human level. Stated differently, in contrast to the protometaparadigm, the neo-metaparadigm can make an issue of the type of being called "existential being" by revealing the structure of contingency unique to the human level. The backdrop to such discussion is made up of a new "natural evolutionary ontology" paired with the neo-metaparadigm, consisting of (i) "existence derived through laws" on the material level (law-derived existence), (ii) "existence designed and constructed through signal-type programs" on the biological level (signal-type constructed existence), and (iii) "existence designed and constructed through symbol-type programs" on the human level (symbol-type constructed existence). The ontologies of Martin Heidegger and Jean-Paul Sartre are incorporated into the general framework of the neo-ontology as hermeneutic/ phenomenological descriptions of types of existence unique to the human level, or "symboltype constructed existence." Heidegger's philosophy gives precedence to the construction of a "theory of human existence" and is seen to have failed in its attempt to create a "general theory of existence" from there, but the neo-ontology paired with neometaparadigm of science starts with a "general theory of existence" and constructs a "theory of human existence" as a part of this. The "evolution of the principle of order" and the "evolution of types of existence" are in a wholly complementary relationship.

\section{Three Types of "Theoretical Causal Relationships" Explaining "Empirical Causal Relationships"}

In this way, the "theoretical causality" of proto-metaparadigm that was painted with "nomothetic causality" can be divided into three with the "nomothetic causality" of the material level, the "signal-type programmatic causality" of the biological level and the "symbol-type programmatic causality" of the human level. In the biological level, genetic information and its boundary conditions inside and outside cells and living organisms are the "cause" and its phenotypes are the "results." In the human level, the baseball rule of "three outs to change innings" (an example of a normative program) normally has three outs as the "cause" under ordinary boundary conditions (contextual factor), and the change of innings is its "result." All are "theoretical causal relationships" different from "nomothetic causality." Theoretical causality of the material level is the theoretical causal relationship of material science, while the theoretical causality of the biological and human levels is the theoretical causal relationship of (semiotic) information science. These both require "empirical adequacy" (empirical causal relationship).

In such cases, signal-type programmatic causality has nomothetic causality as supporting/constraining conditions, while symbol-type programmatic causality has nomothetic causality and signal-type programmatic causality as supporting/constraining conditions. Conversely, the destruction of the ozone layer (material level) originates from changes in the boundary conditions of the laws of physical science as a result of the operation of symbol-type programs, while hybridization and molecular breeding are direct interventions in DNA programs through symbol-type programs.

Preceding this impact of the human level on the material and biological levels, the results of the evolution of life such as organic compounds produced by photosynthesis or soil formation produced by 
worms are interventions in the material level bringing about its changes. Interrelations between the three levels of nature are observed from lower to upper levels and from upper to lower levels.

The shape of everyday life for people that is made up of the "rule-based order of the human level" (simple cases include appointments for dates and meetings) could not be understood using the "pannomotheticism" of proto-metaparadigm. This is the reason the "study of positive law" could not become a science. There have also been attempts to distinguish the "change of innings after three outs" from a "causal relationship" as a "semantic relationship," but this does nothing but reaffirm and fixate the divergence and fragmentation of the humanities and the natural sciences. However, the introduction of the program category threw light on the contiguous nature (same type of identity as programmatic order) and noncontiguous nature (difference between physically constructed signal-type programmatic order and symbol-type programmatic order constructed through a representative intermediary) of human order and biological order.

In the past, Max Weber identified "meaning adequacy" and "causal adequacy" as the two requirements for "sociological rules" (soziologische Regeln), but the former could be interpreted as "symbol-type programmatic causality" and the latter as "the empirical validity of symbol-type programmatic causality," signifying a causal relationship such as that indicated by David Hume. A notable problem with the "empirical validity of symbol-type programmatic causality" is that unlike inviolable laws of physical science or signal-type programs that operate according to physical science and are generally not violated, symboltype programs that operate through a representative intermediary are generally,

and in actual fact, quite often violated.

Suggested by this theory of Weber, neo-metaparadigm divides causal relationships into "theoretical causal relationships" and "empirical causal relationships," with theoretical causal relationship being further divided into the three categories of nomothetic, signal-type programmatic and symbol-type programmatic causal relationships. The empirical causal relationships here are causal relationships in the sense described by Hume. In nomothetic causality, deterministic/stochastic and linear/nonlinear laws are deemed as being inviolable, so there was no need to differentiate between theoretical causality and empirical causality. The two are a unified "causal relationship." However, the definite categorical separation of theoretical causality and empirical causality opened the way to scientifically legitimize the existence of theoretical causality other than nomothetic causality called "laws," that is, theoretical causality called "programmatic causality."

This should be repeated as it is a revolutionary point for the humanities. The "rule-based order of the human level" is a "symbol-type programmatic order of the human level" on par with the "nomothetic order of the material level" and "signal-type programmatic order of the biological level," making up the final part of the "evolution of the principle of order," being positioned in the "scientific view of all nature." This is the destruction of "pannomotheticism" that has continued since the time of Newton. There were also signs of this destruction in some human and social sciences. The reason for this is that physical science cannot be practiced without being conscious of the laws of physical science, human and social sciences cannot be practiced without being conscious of values, norms, styles and rational/irrational decisions but can be practiced without being conscious of the laws of human and social sciences. However, there was no alternative proposal that could rival "pan-nomotheticism" including the radical claim of denying all principles of order.

Weber's "ideal types" that were constructed completely unrelated to genome science are positioned as only cognitive methods or purely cognitive frameworks, but if the ideal types were reversed to be intrinsic to the semiotic information space of society and interpreted as theoretical models of a set of programs existing in society itself, Weber's sociology could be evaluated as being a precursory form of symbol-type 
programmatic science. Another example is the ethnomethodology of Harold Garfinkel, but I would like to discuss this in section $\mathrm{V}$.

At any rate, in the neo-metaparadigm, the scientific constructs of signal-type and symboltype "programs," or in other words "inherent non-law type principles of order" of the biological and human levels could be an alternative proposal for "pan-nomotheticism." Many people who are not scientists would feel that "scientific knowledge and theoretical knowledge had caught up with common knowledge and practical knowledge" with regard to "rule-based order in the human level." The principal factor in holding them back was the spell of the pan-nomotheticism of modern science. As far as nomothetic monism is concerned, this is the obscurity of scientific knowledge and the clarity of common knowledge.

\section{Some Contrastive Views on "Order of Nature" in the Proto- and Neo-Metaparadigms}

The three neo-metaparadigm proposals of "designing science," "nonsemiotic and semiotic information," and "evolution of the principle of order" outlined above are radical, or disconnected from the protometaparadigm in that order. In relation to the most radical proposal of the "evolution of the principle of order," I will examine five views about "order of nature" in the proto- and neo-metaparadigms, and portray the proposals of the neometaparadigm in more detail. The five views are 1) empirical generalizations or empirical rules, 2) the mathematical structure of order, 3) self-organization, 4) a mechanistic view versus an organistic view, and 5) the "boundary condition theory versus the program theory" in interpreting the genome.

1) The first view is empirical generalizations. Empirical generalization propositions (empirically generalized propositions or "empirical rules") found throughout all of nature and all academic fields have been called empirical laws as part of the nomenclature of pannomotheticism, but as a general rule, they are derived from "hybrid explicans" made up of a proper combination of the laws of physical science, signal-type programs, symbol-type programs and their boundary conditions (boundary conditions in the broad sense of the term including temporal initial conditions and the narrow spatial sense of boundary conditions). Both the proto- and neo-metaparadigms share this goal of deriving empirical generalizations based on "principle of order and boundary condition."

The issue is that the space and time to which empirical generalizations are applied differ depending on the predominant type of principle of order. As laws are universal and unchanging for empirical generalizations in which the laws of physical science and their boundary conditions are predominant, the space and time to which they apply is only dependent on differences in boundary conditions (such as differences between empirical generalizations under surface gravity and empirical generalizations under the microgravity of outer space), and are generally applied to a wide range of space and time. However, as not only boundary conditions, but also the actual program can be changed for empirical generalizations in which symbol-type programs and their boundary conditions are predominant, the space and time to which they can be applied are subject to severe restrictions. Those empirical generalizations that are valid under Institution $\mathrm{X}$ may not necessarily be valid under Institution $\mathrm{Y}$. Therefore, empirical generalizations in human and social sciences must always be aware of their applicable space and applicable time. Empirical generalizations relating to gender now under change are good examples. Empirical generalizations assuming existing gender-related programs could change if the program is changed. The programmatic science perspective that empirical generalizations regarding the social participation of women greatly vary depending on the social participation program for women differs from that of nomothetic science. This is a view of positivism peculiar to the neo-metaparadigm of the programmatic science.

The neo-metaparadigm redefines the positivism of the proto-metaparadigm as "lawbased positivism" and proposes a new "program-based positivism." In particular, empirical generalizations in which symboltype programs are predominant differ from physical scientific empirical generalizations strongly tinged with 
"empirical generalizations as given excluding the measures to control boundary conditions," in that there is a need for the scientific understanding of them being "empirical generalizations that are constructed or should be constructed by human hands." In their resistance to law-based positivism, human and social scientists strongly oriented toward change like "constructionists" have a tendency to radicalize in the direction of negating positivism itself. However, the framework of the neo-metaparadigm, which separates "law-based positivism" and "program-based positivism," enables a suitable positioning of positivism within the humanities. "Post-empiricism" that since Kuhn asserts "breaking current theories with new theories" instead of "falsifying current theories with observed facts" suggests a misunderstanding shared among scientific philosophers regarding the Hanson thesis of the "theory-ladenness of observation." That is, "observation laden with theory" and "whether facts laden with theory are observed" are confused without being distinguished. Apart from the Duhem-Quine thesis regarding the "impossibility of crucial experiments," many seem to ignore that the absence of observed facts laden with theory could overturn the relevant theory. This point applies to both law-based positivism and program-based positivism. In terms of the new metaparadigm, certain "cognitive programs" (observations laden with theories) can theoretically be distinguished from certain "cognitive information" (observed facts laden with theories) which is based on the former. Such misunderstandings about the Hanson thesis must not be made the basis of disregard for positivism.

2) The next issue is the need to classify the mathematical structure of order, which neometaparadigm regards as pure artificiality, not as structure inherent in nature or objects, into the mathematical structures applied to empirical order and those not applied to empirical order. The former includes the mathematical structures applied to all empirical order including (1) nomothetic, (2) signal-type programmatic, (3) symboltype programmatic and (4) empirical-generalization-based order. The latter is the mathematical structure of nonempirical order, that is, pure mathematical order.

The mathematical view of science involving deciphering "books on nature written in numbers" that originated in Galileo had a tendency to misconstrue "mathematical structure of order" in general as "laws." However, the neo-metaparadigm separates "laws" and "mathematical structure of order" as two distinct concepts. An income tax program is expressed through formulae, but this is the "mathematical structure of symbol-type programmatic order" and not the "mathematical structure of nomothetic order." These are "rules" and not "laws." Simply put, being expressed mathematically does not necessarily mean being a "law."

The rise of the science of complex systems marks nothing more and nothing less than a paradigm shift from "empirical and nonempirical order with a linear mathematical structure" to "empirical and nonempirical order with a nonlinear mathematical structure." There are "nomothetic complex systems" (nonlinear dynamics and meteorology), "programmatic complex systems" (financial engineering) and "purely mathematical complex systems" (for example, complex systems for arbitrarily constructed examples and games). Complex system theory needs to be differentiated into these three types at least. However, in computer simulations of complex systems, the differences between "game rules," "laws of physics, "genetic programs," "behavioral programs" and "empirical generalizations" are difficult to notice as they are all inputted as "computer programs." For people devoting their research activities to computer simulations, it is not necessary to differentiate the unchanging laws of the physical world from the takenfor-granted rules of chess. However, the noted "complex adaptive systems" put forward by the Santa Fe Institute are "programmatic science type of complex systems" based on the assumption of changeable and adaptable programs, and are not "nomothetic science type of complex systems" (nonlinear dynamics, etc.) based on the assumption of unchangeable and inadaptable laws. The mathematical structure of "nonlinearity" is the same, but each has a different "principle

of order." 
The paradigm shift of the "evolution of the principle of order" and the paradigm shift of "complex systems" are two completely distinct things. The former is a shift from the "pannomotheticism" originating from Newton to the "evolution of the principle of order," while the latter is a shift from linearity to nonlinearity in the mathematical scientific outlook of a

"mathematical structure of order" originating from Galileo. Put differently, there are 4 types of system, which are (1) linear nomothetic systems (classical mechanics, etc.), (2) nonlinear nomothetic systems (nonlinear mechanics, etc.), (3) linear programmatic systems (theory of general equilibrium in economics, etc.) and (4) nonlinear programmatic systems (models of financial markets as complex systems, etc.)

From the perspective of the "evolution of the principle of order," the indication that the form of "the relationship between programmatic order and its mathematical structure" differs from that of "the relationship between nomothetic order and its mathematical structure" is more important than the issue of the nonlinear nature of mathematical order." Nomothetic order as in the force of gravitation, electromagnetic force and nuclear binding force, etc. is given only as its mathematical structure. This means "nomothetic order" and its "mathematical structure" are simultaneous and equal, and the mathematical order is universal and unchanging because it is assumed that the laws are universal and unchanging. However, in the relationship between "special and variable programmatic order and its mathematical structure," the selection of "programs made up of signs in a certain stage of evolution" (including the selection of mathematically constructed programs such as income tax programs) precedes and determines the "mathematical structure" to be applied to the order concerned. Because of this, if the program changes, the applied mathematical structure of the order can also change.

For example, the algebraic structure of the Klein four-group of certain types of kin structure revealed by anthropologist Claude Levi-Strauss and mathematician Andre Weil was interpreted as the "deep structure" as opposed to the programmatic order type of "surface structure" determined on the human side. However, it must be recognized that the "surface structure" as spontaneous or planned programmatic order is in fact logically and empirically antecedent and a pre-given condition to what is claimed to be its mathematical "deep structure." If the "surface structure" of the kin changes, the "deep structure" can change. To borrow a now-inappropriate term from structuralism, the deep structure (mathematical structure of order) does not determine the surface structure (programmatic order), but instead the surface structure (programmatic order) determines the deep structure (mathematical structure of order).

However, the supports/constraints of the laws of physical science in the material level and the signaltype programs in the biological level are pre-given conditions of the human level, and in program selection in which these types of supports/constraints have great significance, one focus of debate is whether the "deep structure" is a direct/indirect effect of the laws of physical science and genetic programs, including the possibility and impossibility of intervention on this on the human side. The "deep structures" based on physical scientific laws or the genome could determine the "surface structure" derived from symbol-type programs except in the case of the deep structure concerned being controlled by human hands.

Modern economics is the most nomothetic social science. Obviously, rational economic programs and their mathematical structure occur simultaneously like in the case of laws. However, this is based on the assumption of the rational criteria for program selection in the form of "homo economicus," and if the logical and empirical antecedence of these criteria is noticed, it should be noticed that the mathematical structure of so-called economic laws differs from that of the laws of physical science in only being the "result of selection" by humans. Thus, the problem is transferred to revealing the values and market structure that motivate rational economic choices.

The discussion above also applies to complex systems science. The universal and unchanging laws of nomothetic complex systems and their mathematical structure are simultaneous and equal, but the mathematical structure of programmatic complex systems is determined by the preceding program 
selection (including, of course, mathematically expressed programs), and not the reverse. If the program changes, the mathematical structure of the order also changes. In particular, if nonlinearity is deemed undesirable in engineered programmatic complex systems, a programmatic intervention is designed to eliminate and overcome such circumstances. The neo-metaparadigm holds that the reason there is no awareness of the whereabouts of such issues, is that the radical differences between the "law" and "program" principles of order (the universality and immutability of the former, as compared to the special and variable nature, or blueprint-like characteristics, of the latter rooted in its constructed nature through signs intrinsic to objects) have not been noticed in "pan-nomotheticism" and fundamental categories have not been established as a result.

The application of the mathematical structure to empirical order should have different meanings for nomothetic order and programmatic order. Although the methodological significance of ensuring "clarity and strictness" of "concepts, propositions and reasoning" of the argument is identical, universal and unchanging order is revealed in the former, but only special and variable order is revealed in the latter. However, in the Galilean mathematical scientific outlook, the latter cannot be distinguished from the former.

3) Self-organization also needs to be differentiated into "nomothetic self-organization" and "programmatic self-organization." Self-organization originating from physics is "selforganization through laws (such as dissipative structure theory)" and the "information" discussed there - such as information and order (certain patterns) formed from fluctuations - is "nonsemiotic information," or merely "differences/patterns in matter" and not "semiotic information." However, self-organization originating from the social sciences is "selforganization through programs" based on the "cognition, evaluation and direction, which are the three major functions of semiotic information." "Programmatic self-organization" with "variable programs" instead of "invariable laws" as its principles of order requires a "primary selforganization theory" handling "self-organization through given programs" and "secondary selforganization" handling the "formation, maintenance, transformation and extinction of the programs concerned." This type of two-layered theoretical structure is impossible and unnecessary in nomothetic self-organization theory. The self-organization theory of the social sciences and engineering, which is widely referred to internationally, is misconstrued as the Prigogine-style self-organization theory, but its substance is programmatic self-organization and not nomothetic self-organization.

In self-organization of the biological level, "nomothetic self-organization" of the material level and "programmatic self-organization" of the biological level coexist as the laws of physical science are directly involved within organisms. For example, the construction of the three dimensional structure of protein is the result of the synthesis of programmatic selforganization in the form of the specific linear sequence patterns of amino acids through genetic programs and thermodynamic nomothetic self-organization based on the sequence patterns of amino acids. However, it is impossible to find "nomothetic self-organization" in the human level without the direct involvement of the laws of physical science or social laws.

If this is the case, why then was "nomothetic self-organization theory" originating from physics accepted in social sciences and engineering? The reason for this is that "decentralized and dispersed (and sometimes participatory) programmatic self-organization" in a contrasting position to "centralized and concentrated (and sometimes delegated) programmatic self-organization" was somewhat pushed by the Hayekian spontaneous order theory reflecting the requirements of the time, and pulled by the lack of program categories, being metaphorically identified with physical self-organization.

In fact, the self-organization in the social sciences and engineering is directed at "decentralized and dispersed (and sometimes participatory)" programs such as "autonomous distributed systems" and their ripple effects. In essence, this is nothing but a "multi-agent programmatic self-organization." Agent-based 
complex systems are no exception in that they are programmatic self-organizing systems. However, programmatic self-organization also includes "single-agent" and "compound/layered-agent" types. The true whereabouts of the problem was not noticed because the proto-metaparadigm did not categorize or theorize the differences in the principles of order between "universal and unchanging laws" and "special and variable programs."

The two systems of law-type and program-type self-organization theory are perfect for a showdown between the proto-metaparadigm and the neo-metaparadigm. The differentiation of the two systems of self-organization is theoretically impossible in the protometaparadigm. That is the reason why the differentiation has not been pointed out. There is no "suitable awareness" because there is no "suitable concept." This is a limitation of inductivism and deductivism, and also the reason an abduction is required in order to make a breakthrough. The program category is one result of this abduction. In summary, the comparison of the two types of self-organization theory is a comparison of the proto- and neometaparadigms of modern science, and one cannot enter this arena if the presence of the neometaparadigm is ignored.

4) The metaphor of "mechanism versus organism" is familiar to the proto-metaparadigm. The physical reductionist interpretation of molecular biology equating organisms to "molecular machines" also utilizes this metaphor. However, the neo-metaparadigm sees this metaphor as being a fundamental failure. The reason is that the mechanism metaphor overlooks the point that the parts of a machine, the spatiotemporal location of the parts and their processes and functions are all products of engineering blueprints, or the greatest characteristics of a machine, which are the use of a "program (blueprint) applied to hardware" and a "material construct containing or realizing a program (blueprint)." The complete penetration of the laws of physical science focused upon by the metaphor is an unavoidable and essential supporting/constraining condition not only for machines but also organisms.

The difference between machines and organisms (below, the former refers to machines and the latter refers to organisms) can all be reduced to characteristics related to programs such as (1) the externality and internality of programs, (2) differences in the evolutionary stages of signs making up programs (mathematical linguistic signs and genetic signs), (3) differences in the format of program creation (free conceiving and mutation), (4) differences in the selection format of programs (voluntary selection and natural selection) and (5) differences in selection criteria (instrument-rational optimization and the inclusive fitness proposed by William Donald Hamilton). Put simply, this is the difference between the "externality" of "symbol-type engineering programs" and the "internality" of "signal-type genetic programs," which both have the laws of physical science as supporting/constraining conditions.

If the structure of the solar system, the structure of machines, the structure of organisms and the structure of society are compared, the structure of machines is far more like the structure of organisms and society than the structure of the solar system with respect to having a "structure constructed through programs" as opposed to a "structure formed through laws." There is no theoretical differentiation between "nomothetically formed structure" and "programmatically constructed structure," that is to say, no distinction between "laws" and "programs" in the proto-metaparadigm, and this similarity/ congruity between machines and organisms could not be discerned.

Machines are not a pre-life entity preceding organisms, but are bona fide post-life entities that are manmade. The proto-metaparadigm was unable to figure out the theoretical implications of this blatantly obvious fact. However, the neo-metaparadigm is able to discriminate between "program-free systems," "external-program systems" and "internal-program systems." Physical science systems are program-free systems, but machines are external-program systems and like organisms and society, they are not program-free systems. This is the reason it can be stated that the "mechanistic versus organistic" metaphor of the proto-metaparadigm, which went completely undoubted, is a failure. 
5) The tension between the "boundary condition theory and program theory" in genome understanding is the core of the tension between the proto-metaparadigm type interpretations and neo-metaparadigm type interpretations in genome science. As mentioned above, the proto-metaparadigm holds the genome to be a boundary condition of the laws of physical science acting in vivo, while the neo-metaparadigm holds the genome to be an evolutionary archetype of the principle of order named program (spatiotemporal blueprint) that appeared on the planet Earth. The boundary condition theory is the view of physical reductionism in biological science, and the genetic program theory can be positioned as an entirely modified, rather newly conceived version of the organicism and vitalism of the past. The two are consistent interpretations within the respective paradigms, and as such, it is difficult to rank them. It provides one example for the commensurability between different paradigms spoken of by Thomas Kuhn.

However, interpretations differ depending on whether the arena, or universe of discourse, is limited and localized to physical science and biological science, or whether it should be expanded, spread and delocalized to cover all sciences including the human and social sciences. Biologists and physicists discuss this issue without considering the human and social sciences. However, as shown in my argument to this point, the neo-metaparadigm brings all sciences into perspective (discussion) and compares the suitability of the "boundary condition theory" and "genetic program theory.

As a result of this comparison, the neo-metaparadigm repositions the genome, which was positioned as "a boundary condition of the laws of physical science acting in vivo," as follows. Firstly, the genome is a genetic program which designs and constructs the boundary conditions of the laws of physical science acting in vivo, and secondly, the details of the program are formed and transformed through Darwinian "mutation and selection" to make the laws of physical science acting under those boundary conditions concerned bring about results desirable for the organism (such as the maximization of the inclusive fitness of the genome as proposed by William Donald Hamilton). This means the commensuability between the proto- and neo-metaparadigms is achieved as far as possible. Put differently, the order of organisms is determined by genetic programs subject to "mutation and selection," and though the genetic programs could not be formed nor operate without supports/constraints of physical laws, the contents of the programs cannot be derived from the laws of physical science. That is, "order based on genetic programs" cannot be restated as "order based on the laws of physical science."

However, one point that is frequently misunderstood about the neo-metaparadigm is that its "technological basis" that is the fundamental and emergent information mechanism of the biological level and human level, or more specifically the actual creation of the "RNA/DNA information mechanism" in the biological level and the "linguistic information mechanism" in the human level, cannot be explained without turning to reductionism. Stated differently, the former is caused by laws of physical science and their boundary conditions, while the latter is caused by the laws of physical science, genetic programs and the boundary conditions of these. This means that the "birth of life" and the "birth of language" cannot be explained any way other than through reductionism. Put differently, the "emergence of programs" and the "emergence of the fundamental technological foundations of programs" must not be confused. The emergence of RNA/DNA type and linguistic type programs rejects reductionism, but the emergence of the technological foundation of RNA/DNA type and linguistic type programs rejects non-/anti-reductionism. It is necessary to clearly state what is reducing or non-reducing.

To simplify the core of the conflict about the genome between the proto- and neometaparadigms, concerning the three processes in organisms which consist of 1) the operation of genetic programs, 2) construction of boundary conditions and 3) acting of the laws of physical science, the "boundary condition theory" fails to distinguish between the first and second steps because it lacks the new "program" category 
as opposed to the traditional "law" category. Here again, without proper concepts, there is no proper recognition.

In addition to this conclusion, if there are no "laws of biological science" separate from the genome and unique to organisms, the fundamental proposition of "pan-nomotheticism" limiting the principle of "order of nature" to only "laws," which has dominated science in the 300 years since Newton, needs to be discarded. The 16th and 17th century modern science originating from the Christian cosmology of the creation of all of nature by God began to be "detheologized/ secularized" in the 18th century, and the abandonment of "nomothetic monism" derived from the "one and only principle of creation" by God signifies the completion of the "detheologization/ secularization" of modern science according to the position of the neo-metaparadigm, though this cannot be acknowledged in the ethos of the protometaparadigm that had become "normal science" in the extended sense of the term of T. Kuhn, with pannomotheticism being self-evident and taken-for-granted.

The destroyed and dismantled concept of "laws" in modern science is reorganized as three basic categories of 1) three types of order principles in nature, 2) empirical generalizations and 3) mathematic structure of (empirical/ nonempirical) order. Although "Laws" in the neo-metaparadigm are held to form the foundation of all of nature as one of the three types of principle of order in the form of the principle of order for the material level, or the laws of physical science, these "laws" are as such only given a localized position. The programmatic order of the biological level is supported and constrained by the laws of physical science, but cannot be reduced to the laws of physical science. Likewise, the programmatic order of the human level is supported and constrained by physical laws and biological programs, but cannot be reduced to those principles of order. Of course, antiphysical reductionism or anti-reductionism in general is not an uncommon assertion. However, proto-metaparadigm of modern science was unable to comprehensively and systematically theorize this. The neo-metaparadigm, which introduces evolutionary "information" categories and evolutionary "order principle" categories, brought about a cataclysmic change to modern science in the form of its "shift in the metaparadigm" to finally achieve this.

\section{A Plan for the New Academic System}

To summarize the above, if the first point is the proposal of "designing science" counterposed and juxtaposed against "cognizing science," the second point is the proposal of signal-type and symbol-type "information science" (not only "computer science as both types of information science" but also "genome science as signal-type information science" and "human and social sciences as symbol-type information science") counterposed and juxtaposed against "material science," while the third point is nothing else than the proposal of signal-type and symbol-type "programmatic science" counterposed and juxtaposed against "nomothetic science."

This is a basic framework utilizing "laws" as the principle of order for "matter-energy space" and "programs" as the principle of order for "semiotic information space." Therefore, material science and nomothetic science belong to the same scientific field, with the former focusing on the constituents of objects and the latter on their principle of order. In the same way information science and programmatic science (as cognizing science) are identical, with the former focusing on the constituents and the latter on the principle of order.

Programmatic science is divided into two, with one aspect being the above "programmatic science as cognizing science" counterposed against "nomothetic science," and the other aspect being "programmatic science referring to designing science," or "designing science" itself. The former is called programmatic science, or if necessary cognition-oriented programmatic science and the latter is called designing science, or if necessary designoriented programmatic science. 
The programmatic science including both cognition-oriented and design-oriented types was named "programmology" taking the suggestion and advice of Dr. Setsuya Fujita, who is an internationally-known creative brain scientist, presently the Head of the Louis Pasteur Center for Medical Research in Kyoto and the Former President of Kyoto Prefectural Medical College. The proto-metaparadigm of modern science has produced nomothetic sciences of the material level of nature, whereas the neo-metaparadigm will produce cognition-oriented programmologies of the biological and human levels of nature. In terms of traditional academic fields, physical science corresponds to "material science and nomothetic science," biological science corresponds to "signal-type information science and signal-type cognition-oriented programmatic science," and the human and social sciences correspond to "symbol-type information science and symbol-type cognition-oriented programmatic science." In addition, logic and mathematics as formal or methodological science belong to "symbol-type information science and design-oriented and cognition-oriented symbol-type programmatic science" in "pure representative space" in terms of the neometaparadigm, which is certainly not nomothetic science of material space. As is commonly known, "information science" tends toward computer science, such as bioinformatics and legal informatics often being understood as genome science, proteinomics and precedent studies utilizing computers in research methods (computer simulations and computer databases). However the stance of the neo-metaparadigm is that "information science" is one of the two major categories of all academic pursuit that should be counterposed and juxtaposed against "material science." Unfortunately, overcoming contradictions between the "academic structure" and "institutional structure" of science requires time on a historical scale.

To introduce the perspective of philosophical history, the Christian worldview of "creation of the world by god" was an archetype or precursory form of the modern scientific worldview of "formation of the world through laws." The neo-metaparadigm reinstates this "creation" philosophy as "design" in two respects. The first is cognition-oriented programmatic science handling the self-design (self-organization) of the biological and human levels in the "design of nature not through god, but through nature itself." The other is designing science (design-oriented programmatic science) handling the "design intervention of humans on all of nature" as a special exception.

However, if a different perspective is taken, this reinstatement of the "creation" philosophy as "design" wipes away the last vestiges of Christian worldview in the name of "nomothetic monism" or "pannomotheticism," which philosophically originated from "the creation of the world by a single God." Introducing the "category of self-designing by nature itself" into the neo-mataparadigm finally breaks away from that pseudo-theological worldview, adopting a scientific worldview or specifically marking a complete transition to an "evolutionary view of nature." Instead of "the creation of the entire world by god or laws," the natural evolutionary ontology that is in unity with the neo-metaparadigm of science that begins with "material existence created through the laws of physical science," and goes through "biological existence constructed through signal-type programs" to "human existence constructed through symbol-type programs" is an extension of Darwinism and signifies the complete penetration of evolutionary thought in the metaparadigm of science. It is a culmination of the "dereligionization" of modern science that has been underway since the 18th century.

For the proto-metaparadigm based on the model of law-based order on the material level, "laws" were the stars of modern science, but for the neo-metaparadigm inspired by the genome-based order of the biological level and rule-based order of the human level, "nomothetic monism" was the last bastion of monotheistic science. The neo-metaparadigm names the framework made up of the following propositions "Pan-Darwinism:" 1) the birth of a set of signs and programs (RNA/DNA and the genome) on the planet Earth, 2) semiotic evolution and evolution of program form (reaching to the stage of languages and linguistic programs), 3) emergence and change of programs, 4) exogenous/ endogenous and ex post/ ex ante selection (adoption/elimination) of programs, 5) selection criteria of programs and 6) inter/intra- 
generation type of storage and communication of selected programs. It understands these propositions to be the fundamental empirical generalizations penetrating the biological and human levels of nature (in fact, the scientific positioning of these "Pan-Darwinist generalizations" shows the Achilles heel of the neometaparadigm).

The core of this Pan-Darwinian framework is the "primary and secondary self-organization theory." In terms of the biological level, the entire process from the genotype to the phenotype is to be explained by the "primary self-organization theory" regarding genetic programs and the biological evolution theory is nothing else than the "secondary self-organization theory" handling the formation, maintenance, transformation and extinction of such genetic programs. In terms of the human level, social construction through linguistic programs is to be explained by "primary self-organization theory" and the formation, maintenance, transformation and extinction of such linguistic programs is to be explained by "secondary self-organization theory."

Put differently, primary self-organization theory is a theory on "the program as an explicans," and secondary self-organization theory is a theory on "the program as an explicandum." Thus, "programmatic self-organization theory" forms a generalized concrete example of programmology. This illustrates the fundamental difference compared to the "nomothetic self-organization theory" of Prigogine and Haken. The Pan-Darwinism or extended Darwinism that I speak of is, in the proposed new academic system, positioned as a basic framework for uncovering historical changes particular to the biological level and human level (evolution of semiotic information) that are of a different type than historical changes of the material level (material evolution), or historical changes transmitted through "changes in semiotic information space". I would like to repeatedly emphasize this point.

Looking inside the social sciences, ethnomethodology founded by Harold Garfinkel pointed out above all the simultaneous progress of the two interpenetrating processes of "the achievement of interaction through the common knowledge of actors and contextual factors" and "the explanation of achieved interaction through the common knowledge of actors and contextual factors" in the midst of one and the same interactive process (the simultaneous progress of "construction and its explanation" unique to symbol-type programmatic construction needs explaining, but I will omit this as it is not the topic of this paper). This just corresponds to the assertion in the symbol-type programmatic science about the simultaneous progress of the two interpenetrating types of informationprocessing, that is, "the social construction of reality through symbol-type programs of actors and boundary conditions (contextual factors)" and "its explanation also through symbol-type programs of actors and boundary conditions" occurring in the midst of one and the same constructive process. The reason for this is that the set of programs included by common knowledge forms the core of symbol-type programs in general.

Ethnomethodology initially faced strong criticism in American sociological circles as the "abandoning and dismantling scientific sociology," but it advocates a "new form of science" and is not a "denial of science." Although it may not have been a conscious step, this implied a "radical paradigm shift from nomothetic science to programmatic science." Even without a name, insight is insight. This is the insight of utilizing the concept of "common knowledge" or "ethnomethods" as Garfinkel called them in place of the "program" category.

In addition to ethnomethodology, all sociological thinking, such as phenomenological sociology and symbolic interactionism, that I previously called the "meaning school" had the latent potential and the opportunity for this paradigm shift. However, ethnomethodology was the only one to reach the stage of a theoretical and formal framework effectively equal to the argument of programmatic science. This is how strong the unknowing monotheistic spell of unconscious pan-nomotheticism over sociologists was. Garfinkel was effectively the only pioneer of the neo-metaparadigm in the human and social sciences. 
As another example, let us also apply the neo-metaparadigm to "engineering" with the compound academic form of knowledge. Engineering is divided into "Engineering I" and "Engineering II." "Engineering I" is a "cognition-oriented programmatic science" aimed at explaining the accomplished material and biological artificial programs, and "Engineering II" is a "design-oriented programmatic science" aimed at creating new material and biological artificial programs. According to the curriculum of Japanese universities, the former was the subject of the "graduation thesis" and the latter was the subject of the "graduation design." The program explanation of artificialities in "Engineering I" is nothing else than the "science of material and biological artificiality" contrasting with the "science of material and biological nature" as held by Dr. Hiroyuki Yoshikawa. Here, "science" refers to cognizing science, and "Engineering I" is the adequate reason to have an "Engineering Department graduation thesis" (science of artificiality) of equal standing to a "Science Department graduation thesis" (science of nature) based on the protometaparadigm limiting the purpose of science to cognition ("science = cognizing science" monism). Dr. Yoshikawa objected to the internationally and domestically established academic view that engineering is not science, claiming that even if Engineering II may not be science, Engineering I is "science of artificiality" similar to the "science of nature."

The neo-metaparadigm's proposal of the "program category" and "designing science" (as mentioned above, this is "science aimed at design itself" and not "science aimed at the cognition of design") transforms this situation. It marks the entry into science of "engineering as a practical knowledge" that is inseparable from the history of humankind. At any rate, although engineering may be supported/constrained by "nomothetic science," it is not "nomothetic science" itself, but the "programmatic science" in both senses mentioned above, that is to say "cognition-oriented programmatic science of material and biological artificialities" (Engineering I) and "design-oriented programmatic science of material and biological artificialities" (Engineering II).

Physical science for "biological science as information science," together with physical science, biological science and the social and human sciences for "engineering as cognition-oriented and designoriented programmology" and others were named "supporting/constraining sciences" or "basis sciences" necessary for the respective scientific fields. For example, molecular biology and genome science cannot exist without physical science as their basis. However, the closeness of relationships between particular individual sciences and their basis sciences vary greatly depending on the influence of the relevant basis science as supporting/constraining conditions.

In general, more than actually being relatively independent or autonomous from the direct supports/restrictions of physical science and biological science, the human and social sciences are able to be relatively independent or autonomous at least with regard to the "operation of programs through a representative intermediary (see a suicide bombing)." Rather, the mutual and cross-cutting supports/constraints within the human and social sciences are more conspicuous.

According to the neo-metaparadigm, biological science is the same as "the social and human sciences" with respect to a "cognition-oriented programmatic science" and is the same as "physical science" in that "program operation is in accordance with the laws of physical science." Put differently, biological science is an "amphibious science" bridging the gap between the physical sciences and the human and social sciences.

Since the appearance of genome science, there had already been a split between "physical science as nomothetic science" and "biological science as non-nomothetic science" (cognition-oriented programmatic science) within the natural sciences, but the two-way division into the natural sciences and the human and social sciences was finally destroyed, and made way for the three-way division of material science (science of the material level), biological science (science of the biological level) and the human and social 
sciences (science of the human level). The reason for this is that the neo-metaparadigm rejected the physical reductionist interpretation of biological science in the protometaparadigm, and maintains it cannot be reduced to the physical science nor to the social and human sciences in the capacity of "signal-type information science and signal-type programmatic science," gaining an academic identity unique to biological science.

If engineering is the programmatic science cognizing and designing "material and biological artificialities," the social and human sciences, if extended beyond policy science and normative science to include social and human designing science in general, are programmatic sciences cognizing and designing "social and mental artificialities" (social artificialities such as family, company, city, state, custom, law and institution in addition to mental artificialities such as literature, music, art, ethics, religion, science and values). More specifically, although there are differences in whether their object is material and biological artificialities or social and mental artificialities, and as a consequence, there are qualitative differences in their supporting/constraining sciences (basis sciences), but these are equally the "cognitionoriented/ design-oriented programmology of artificialities." This makes "engineering" and "the human and social sciences" the same type of academic study. This type of surprising knowledge brought about by the neo-metaparadigm should bring major changes to the traditional academic system.

In this way, if a basic system of science that is simple and clear can be constructed according to the neo-metaparadigm without being bound by the current institutional structure or intellectual vested interests, science can be split into 1) physical or material science covering the material level including material artificialities, 2) biological or life science covering the biological level including biological artificialities and 3) the human and social sciences that cover the human level, or social and mental artificialities. Each of these can be further broken into A) a division of cognizing science and B) a division of designing science. Current science can already be said to have achieved this type of potential structure. The construction of a basic structure merely elicits this.

Computer science is the only one that does not fit properly into this basic system, and there are two conceivable ways of responding. One is the traditional notion of defining computer science as "methodological science" like logic and mathematics instead of an "object science" or as a "formal science" instead of an "empirical science." Another is computer science as "object science" or "empirical science," and this perspective is as follows. Computer science is a science that covers the fourth stage of natural evolution based on computers created as a mental artificiality (this could provisionally be called the "computational or computing information level of nature"), given a new position alongside logic and mathematics as a cognition-oriented/ design-oriented programmatic science in pure representative space.

The computational information level of nature following on from the material level, biological and human levels existed in infancy with the appearance of "logic and mathematics as mental artificialities or constructs," but the development of computers gave a solid material shell or foundation to the infant computational information layer making it externalized, extended, autonomous and high-speed. The bold interpretation of computer science as corresponding to the "fourth stage of natural history" that evolved from the "material level" to the "biological level," then the "human level" and finally the "computational information level" provides a convincing explanation of the massive role of computers in modern society (including the development of robots and the Internet as "the collective brain of humankind") and the significance of computer science in academia at present (including "simulation science" as a "virtual experimental science"). If that is the case, it is a natural result that computer science takes information science by storm. This is emergence of "higher brain functions that are externalized, globalized, given autonomy and accelerated," and their cognition and design are held to be the fourth field of empirical science following on from material science, biological science and the human and social sciences. 
Since the big bang and then the birth of the planet Earth, evolution of the material level has been manifested in the evolution of "material space" unrelated to semiotic information space, but since the birth of life, natural evolution on Earth has been succeeded by evolution of the biological level and human level, which is mediated by the irreversible cyclic processes of formation, maintenance, transformation and extinction of "semiotic information space." In post-life evolution, evolution of "material space" such as molecular evolution, created substances, devices and machines are all mediated by some type of change of "semiotic information space," such as variations in genetic information and cultural information. In terms of the "matter-semiotic information" dualism throughout the biological and human levels, the birth and autonomy of the "computational information level" within the human level is nothing else than one extreme of the "evolution of semiotic information space" following on from the "evolution of material space."

The concept of "evolution" including cosmic evolution, biological evolution and the evolution of human society is hard to define, but I will provisionally define it as the "irreversible change of nature." However, application of this definition to the evolution of human society is fraught with problems. It will have to be an issue for the future.

The concept of an academic system including logic, mathematics and computer science as a fourth academic field alongside material science, biological science and the human and social sciences is an internal requirement of the academic system itself corresponding to the levels of nature, but also a product of the sociology of knowledge underpinned by the difference between seeing the advanced information society as "a page in the history of humankind" or as a "a page in the history of nature." For example, the Internet is an enormous information mechanism that is able to externalize, globalize, give autonomy to and accelerate both sensorimotor "real-time information processing" and mental/linguistic "virtual information processing" by the neural system, while simulation science enabling various types and scales of virtual experiments is a future-oriented form of science that promises great advances in response to the "computational information level" on the planet Earth.

Without the metaparadigm shift from "matter" monism to "matter and semiotic information" dualism in the biological and human levels, the idea of "the computational information level as a fourth stage of natural evolution" and the concept of "computer science as a fourth field of science" cannot be properly placed within scientific view of the world. If the "material monism" and "nomothetic monism" of the protometaparadigm were applied to both the biological and human levels, this type of problem could not be solved. Meanwhile, it is undeniable that theoretical frameworks peculiar to the humanities such as phenomenology, hermeneutics, "language game," post-structuralism, constructionism, etc. exist. However, such frameworks peculiar to the humanities cannot be positioned within the proto-metaparadigm of modern science, and are completely diverged and cut off. The proto-metaparadigm of modern science is now almost useless for researchers in the humanities.

The intention of the neo-metaparadigm is not to indirectly seek ways to overcome the cognitive and practical bottlenecks brought about by the proto-metaparadigm of modern science within theories, ideas, ethics and philosophies unique to the humanities that remain diverged from the proto-metaparadigm, but instead to first of all change the proto- metaparadigm, or attempt to achieve this through a "metaparadigm shift in modern science itself." Put differently, this is the establishment of a "new scientism" in the world of knowledge (although that terminology may invite misunderstanding) based on the "neometaparadigm of modern science." The "scientism of the proto-metaparadigm" and the "scientism of the neo-metaparadigm" are continuous but also disconnected. This discontinuity is based on the "Three Big Turns" of the neometaparadigm, which are the integration of cognizing science and designing science, derivative dualism originating from Ur-monism and the evolution of the principle of order. 


\section{The Scientific Historical Significance of Neo-Metaparadigm of Science}

I have called this neo-metaparadigm "The Second Scientific Revolution in Capital Letters." The reason for this is that according to the nomenclature of scientific historians, the paradigm shifts of individual sciences as discussed by Thomas Kuhn (paradigm shift in physics, paradigm shift in biology, paradigm shift in economics, etc.) are called "scientific revolutions" (common noun) in small letters and plural form, while formation of modern science itself triggered by the establishment of classical mechanics, or the paradigm shift of science as a whole (from classical, medieval learning) is referred to as "The Scientific Revolution" (proper noun) in capital letters and the singular form with a definite article. My proposed title of "The Second Scientific Revolution in Capital Letters" is distinct from the so-called second scientific revolution that occurred in the 19th century with the "institutionalization of science," and is actually an attempt of historical comparison with "The First Scientific Revolution in Capital Letters" marking the establishment of orthodox modern science in the 17th century.

Based on the above philosophy of "infinite progress of empirical self-reference distinguished from infinite regress of logical self-reference," it is possible that there may be a third, fourth and subsequent Scientific Revolution in Capital Letters, and if that is the case, the "Scientific Revolution in Capital Letters" will become a common noun referring to the general phenomenon of a "metaparadigm shift in science as a whole." I would like to stop counting "Scientific Revolutions in Capital Letters" at the "second" one, but this is no more than a belief.

The "design" in designing science signifies the design of symbol-type and signal-type "programs." Symbol-type and signal-type "programs" are "a type of semiotic information" as a set of signs. Thus, the heart of "The Second Scientific Revolution in Capital Letters" converges on the introduction of the evolutionary "information" categories of "nonsemiotic and semiotic information." The three major propositions of the neo-metaparadigm comprising "designing science," "information categories" and "program categories" are integrated around the core of "information categories." This is the reason the neometaparadigm is also called "the informatic turn of knowledge," and why I believe the origin of my neometaparadigm can be found in my evolutionary semiotics published in 1967.

This is a modern academic revival of the 2,300-year-old category of "eidos" or "form" proposed by Aristotle. However, it is obvious that Aristotelian philosophy that is ignorant of semiotics does not theorize about the differentiation between nonsemiotic eidos and semiotic eidos. Near the beginning of this keynote report, I put forward the question of whether genome theory is more revolutionary than relativity theory and quantum theory, but now the answer should be clear. Relativity theory and quantum theory signify a Kuhn-style paradigm shift of an individual science of physics under the proto-metaparadigm of modern science, but genome theory is a paradigm shift of an individual science of biology while also being a catalyst for the metaparadigm shift of modern science as a whole. This is similar to Newtonian mechanics being a paradigm shift within the individual science of physics while also being a catalyst for the metaparadigm shift from classical or medieval study in the 17th century. Regrettably, many scientific historians, to date, do not realize that "genome theory" is more revolutionary than "relativity theory and quantum theory" owing to the lack of the notion of metaparadigm shift.

The "genomic turn" of biological science, the "linguistic turn of the human and social sciences" and the "IT turn of engineering" are three "informatic turns" characteristic of the late 20th century, and it is no overstatement to say that the human and social sciences have at last come to play a part in modern science originating in the 17th century due to these "informatic turns." The "Three Big Turns" advocated in the neo-metaparadigm of modern science have special significance for the human and social sciences, which have been "alienated from the metaparadigm of orthodox science." 
However, the above significance of the neo-metaparadigm in scientific history is based on an internal approach. In closing, I would like to mention the significance of the neometaparadigm in scientific history from the perspective of an external approach. While assuming the straightforward basic system of science mentioned above that could be considered to be underlying, various hybrid forms and cross-over forms are formed based on social requirements. One example is the Mode 2 production of knowledge suggested by Michael Gibbons and others.

However, from a comprehensive and generalized perspective, the hybrid type most strongly required by "science for society" is the "cognizing science and designing science" that cover "material, biological, social and mental artificialities," or "artificialities system science," which I proposed in the 18th term of the Science Council of Japan. Obviously, "mental artificialities" include god and an absolute being along with logic and mathematics as mentioned above. In the near future, the products of all fields of science will undoubtedly face questions not only about their own particular significance, but also their direct and indirect relationships with "artificialities system science." In fact, they should be subject to such questions.

If the trend of the first phase of science starting with the First Scientific Revolution in Capital Letters of the 17th century was "science for science," the trend of the second phase of science starting with the Second Scientific Revolution in Capital Letters of the mid-20th century is "science for society" and "artificialities system science" is the academic form making up its core. "Sustainability Science" is one "artificialities system science" that has already manifested itself. The Second Scientific Revolution in Capital Letters is a radical revolution of not only the internal structure of science, but also its external structure. If "physics" was the symbol of the internal and external structure of science brought about in the First Scientific Revolution in Capital Letters, the internal structure brought about by the Second Scientific Revolution in Capital Letters is the basic system described above based on the neo-metaparadigm, and I believe the external structure is symbolized by "artificialities system science" able to comprehensively cover the specific details of the "research contract between society and the scientific community." As this keynote report focused on the internal structure of science, there was no room to speak about the "artificialities system science" deeply related to the external structure of 21 st century science. The reason for this is that the details of artificialities system science are based on the "neo-metaparadigm" including being a programmatic science and not a nomothetic science, and as a result cannot be understood without basic knowledge of the preceding neo-metaparadigm.

However, I would like to emphasize that from an external perspective of science, artificialities system science prescribed to be an "overall cognition-oriented/design-oriented programmology cutting across the humanities and natural sciences" with "the laws of physical science on the material level" and "signal-type programs on the biological level" as supporting/constraining conditions while having "symbol-type programs" unique to the human level as principles of order is the final goal for modern science beginning with "physics as a cognizing type of individual science." This "artificialities system science" cannot stand up to the "cognitive monism," "material monism" and "nomothetic monism" of the proto-metaparadigm, and is a form of science that is not possible without the "Three Big Turns" of the "integration of cognizing science and designing science," "derivative dualism originating from Ur-monism" and the "evolution of the principle of order" that are introduced in the neo-metaparadigm. It is needless to say the "new academic system" proposed here should be shared by artificialities system science and should form its academic basis. In conclusion, the "Three Big Turns" involve a thorough reconsideration of modern science as a whole that has long been viewed as "normal science," and I may go so far as saying that this is a radical metaparadigm shift proposed for the first time 300 years after the birth of modern science. 
For details on the "neo-metaparadigm" and "the informatic turn" of knowledge and "the Second Scientific Revolution in Capital Letters" this paper is based upon, please refer to the Report by the New Academic System Committee established in the Steering Committee of the Science Council of Japan titled "Atarashii gakujutsu no taikei - shakai no tame no gakujutsu to bunri no y.g. [A New Academic SystemScience for Society and the Integration of the Natural Sciences and the Humanities]", Chapter 7 (Yoshida, T.), "Rironteki/ ippanteki 'atarashii gakujutsu taikei' shiron [An Essay on a Theoretical and Generalized New Academic System]", Japan Science Council, and Yoshida T., "Kindai kagaku no paradaimu shifuto shikateki 'j.h.' gainen no k.chiku to 'puroguramu kagaku' no teish. [The Paradigm Shift of Modern Science - the Construction of an Evolutionary Information Concept and Proposal of Programmatic Science], Heisei 8 nendo - gakujutsu kenky. s.g. ch.sa h.kokusho [1996 Academic Research Investigation Report], Science Council of Japan, 1997, etc.

With regard to "artificial system science," refer to Yoshida T., "Fukangata kenky. to ha nani ka: jink.butsu shisutemu kagaku no teish. to kagakuron no paradaimu tenkan [What is Bird's Eye Research? A Proposal of Artificial System Science and the Paradigm Shift of Science]", Gakujutsu no d.k. [Academic Trends] Vol 5 No. 12, Science Council of Japan, 2000 and Yoshida T., "Atarashii gakujutsu taikei' no hitsuy.sei to kan.sei [The Need for and Potential of a 'New Academic System']" Gakujutsu no d.k. [Academic Trends] Vol 6 No. 12, Science Council of Japan, 2000.

A list of 30 key papers on the neo-metaparadigm can be found at the end of Yoshida, T., "Kindai kagaku no meta paradaimu tenkan: hitotsu no shiron [The Metaparadigm Shift of Modern Science: A Proposal]" Gakujutsu no d.k. [Academic Trends]Vol 8 No. 10, Science Council of Japan, 2003. 